\title{
Introduction of the Cost-Effectiveness Studies of Fracture Liaison Service in Other Countries
}

\author{
Yong Han Cha' ${ }^{1}$, Yong-Chan $\mathrm{Ha}^{2}$, Jae-Young Lim³ ${ }^{3}$, Woo-Suk Kim ${ }^{1}$ \\ ${ }^{1}$ Department of Orthopaedic Surgery, Eulji University Hospital, Daejeon; \\ ${ }^{2}$ Department of Orthopaedic Surgery, Chung-Ang University Hospital, Chung-Ang University College of Medicine, Seoul; \\ ${ }^{3}$ Department of Rehabilitation, Seoul National University Bundang Hospital, Seongnam, Korea
}

Corresponding author

Yong-Chan $\mathrm{Ha}$

Department of Orthopaedic Surgery, Chung-

Ang University College of Medicine,

102 Heukseok-ro, Dongjak-gu, Seoul 06973,

Korea

Tel: +82-2-6299-1577

Fax: +82-2-822-1710

E-mail: hayongch@naver.com

Received: December 11, 2019

Revised: January 21, 2020

Accepted: February 3, 2020
Osteoporosis and osteoporosis related fractures contribute a large part of the medical cost in developed countries. Considering the preventive effect of osteoporotic medications, high rate of mortality and complications, poor quality of life after osteoporosis related fractures, the growing trend of older populations in the future, osteoporosis and osteoporosis related fractures are important targets of preventive treatment and also targets of socioeconomic cost reduction. Treating osteoporosis and preventing osteoporosis related fractures have become an essential element in Korean medical system. Despite the various differences in the health care system, hospitals in many other countries are operating fracture liaison service and they have confirmed its cost-effectiveness. In Korea's health care system, further research on cost-effectiveness as well as its clinical effects is needed.

Key Words: Hip fractures · Osteoporotic fractures · Secondary prevention

\section{KOREAN AGING AND ECONOMIC BURDEN}

According to the 2019 Organization for Economic Co-operation and Development (OECD) health statistics, the life expectancy of Korean-born children in 2017 is reported to be 82.7 years old, which is the same as Norway and which is close to 84.2 years old in Japan.[1] One report on future life expectancy in 35 industrialized countries predicts that life expectancy will be the highest in the world for both men and women born in 2030.[2] In 2017, life expectancy was over 20 years at age 65 and the world's highest rise rate of the elderly population 65 years or older is observed in Korea.[2] However, $81.5 \%$ of these ages assess their health

Copyright (C) 2020 The Korean Society for Bone and Mineral Research

This is an Open Access article distributed under the terms of the Creative Commons Attribution Non-Commercial License (https://creativecommons.org/licenses/by-nc/4.0/) which permits unrestricted non-commercial use, distribution, and reproduction in any medium, provided the original work is properly cited.

\section{KSBMR} status as poor or fair, which is very high compared to an average of $56.8 \%$ in 35 OECD countries. This change is also observed in medical facilities with an increase in the elderly population. Number of long-term care beds in facilities and hospitals were 60.9 per 1,000 population aged 65 and over.[2] This is an increase of 36.1 compared to 2007, which is the highest increase compared to the average -3.4 in 24 OECD countries over the same period. In addition, Korea's medical expenditure trend is also the highest in the world. Annual growth in health expenditure per capita was 5.4\% in 2008 to 2013 and 7.3\% in 2013 to 2018.[2] According to the 
National Health Insurance Comprehensive Plan of the Ministry of Health and Welfare, medical expenditure was expected to be 62.29 trillion won in 2018 , and it is expected to increase significantly to 94.32 trillion won in 2023.[3] However, despite the rising medical expenses, the government's medical expenditure on long-term care is only $0.6 \%$ of growth domestic product, which is less than half of the OECD average of $1.7 \% .[2]$

\section{SOCIOECONOMIC BURDEN OF OSTEOPOROSIS \& OSTEOPOROTIC FRACTURE}

The debate on how to reduce the cost of health care due to the increasing aging population has emerged as an important social issue in socioeconomic aspects as well as in health care systems. Among senile diseases, osteoporosis and osteoporosis related fractures contribute a large part of the medical cost in developed countries.[4-6] Considering the preventive effect of osteoporotic medications, high rate of mortality and complications, poor quality of life after osteoporosis related fractures (especially in hip fractures), the growing trend of older populations in the future, osteoporosis and osteoporosis related fractures are important targets of preventive treatment and also targets of socioeconomic cost reduction.[7] Cost of Medicare programs in the US are reported to increase by $50 \%$ by 2020 compared to 2012, and most of these are expected to be caused by ages 65 and older.[8] In the US, the total cost of fracture care with osteoporosis in 2005 is estimated to be $\$ 17$ billion and increase to $\$ 25$ billion by 2025.[8,9] In the analysis of the health care costs of osteoporotic fractures over 50 years old using the Korea national claim database from 2008 to 2011, Kim et al. [10] reported that total estimated healthcare costs of osteoporotic fractures was $\$ 722$ million in 2011, and this is an increase of $31.6 \%$ compared with 2008. During this period, the number of osteoporotic fractures increased by $28.9 \%$ and the mean healthcare cost was highest for hip fractures (\$8,302 in 2011). In 2016, the number of hip fractures was 35,729 and it is expected to increase by 1.4 times to 51,259 by 2025.[6] In Australia, direct or indirect medical expenditures for osteoporosis and osteopenia over the age of 50 are estimated at 2.75 billion Australian dollars (AUD) in 2012 and 3.84 billion AUD in 2022.[11] A study examining the economic burden of care- givers in hip fracture patients reported that $20 \%$ of caregivers felt a high economic burden and even increased depression scores at 6 months after hip fracture.[12] Therefore, many countries are working to reduce medical costs for osteoporosis and osteoporosis related fracture, one of which is fracture liaison service (FLS).

\section{INTRODUCTION OF COST- EFFECTIVENESS OF FLS}

There are various reports of FLS for the prevention of osteoporotic secondary fractures.[13] These studies implemented various types of FLS services and reported good results in increased rates of osteoporosis medication and bone mineral density (BMD) testing, high fracture prevention rate.[7] Nevertheless, the overall implementation of all hospitals in countries where FLS is implemented is not possible because the costs associated with FLS settings are a barrier.[14] Therefore, this review introduces reports on cost-effectiveness among FLS reports of other countries.

\section{Glasgow FLS in United Kingdom}

West Glasgow FLS, established in 1999, covers all men and women who have had low-trauma fractures over 50 years old.[15] Patient identification is performed by an osteoporosis nurse specialist, assessment of osteoporosis and fracture risk is performed in the osteoporosis nurse specialist fracture risk-assessment clinic. The patient is then sent to the general practitioner (GP) and medication is started. A cost-effectiveness study of FLS reported by McLellan et al. [14] compared the FLS pathway with the usual pathway. The FLS pathway has 2 pathways depending on the assessment of osteoporosis and is further subdivided according to the use of osteoporosis medication and performing of dual energy X-ray absorptiometry (DXA). The usual pathway has 3 pathways: assessment by GP, hospital assessment, and no assessment and is further subdivided according to the use of osteoporosis medication and performing of DXA. Analysis of the database revealed that $74 \%$ of patients in West Glasgow FLS and $15 \%$ to $38 \%$ of patients in usual care needed treatment and they designed a Markov model using this ratio. New vertebral fractures were excluded due to their low cost and severity, and included only hip, wrist and humerus fractures. Evaluation contents for this study were number of refrac- 


\section{JBM}

tures, life-years, and quality adjusted life-years (QALYs; a unit of measurement of both the quality and quantity of life lived).

When 1,000 hypothetical cohorts were applied to the Markov model, the number of patients receiving medication was 686 in the FLS pathway and 193 in the usual care pathway. Compared with the manual care pathway, the FLS pathway was able to prevent 18 fractures, resulting in a cost savings of $£ 312,000$. In addition, FLS pathway gained 3 life-years, 22 QALYs, and saved 266 hospital bed days. The cost of assessments was $£ 98,000$ and $£ 14,000$ for the FLS and usual care, respectively; the cost of medications was $£ 292,000$ and $£ 85,000$, respectively. Overall, the FLS saved an estimated $£ 21,000$ over the lifetimes of 1,000 patients.

\section{FLS of John Hunter Hospital in Australia}

Most cost-effective analysis studies of FLS have analyzed its economic effects by calculating the current level of medical use or cost, and creating a model for predicting medical costs. However, Major et al. [16] analyzes the economic impact of FLS, including the past actual direct medical costs charged to patients in the FLS group and patients in the usual care group and all costs used to run the FLS office in the hospital where the FLS was implemented. This study was conducted on patients over 50 years of age who visited the emergency department with minimal trauma fracture from July to December 2010. The medical cost and refracture fractures were checked for 3 years. There were 515 FLS groups and 416 usual care groups. The mean age was 77 and 79 years, respectively. The medical costs of the FLS group included the wages of nursing staff, the paper, postage and telephone costs involved in operating the FLS, and the cost of medication and osteoporosis evaluation and the cost of re-fracture treatment.

FLS could reduce the risk of actual fractures by $29 \%$ and prevent 62 refractures per 1,000 patients. The cost of implementing FLS for 1000 patients over 3 years was $\$ 2,804,378$, including $\$ 343,753$ for the FLS operation and $\$ 2,460,624$ for the treatment of 150 refractures. In contrast, in the usual care group, only $\$ 3,421,653$ of treatment costs for 212 refractures were used and there was no cost for fracture prevention. In conclusion, FLS saved $\$ 617,275$ per 1,000 patients over a 3-year period.

\section{Cost-Effectiveness Studies of Fracture Liaison Service}

\section{Fracture clinic screening (FCS) program in Canada}

In 2007, the FCS program was introduced at 31 outpatient fracture clinics in Ontario, Canada.[17] The FLS covers patients over 50 years of age who have experienced fragility fractures and enrolled 37,920 patients in the program from 2008 to 2013 . The study analyzed not only the FCS program but also the cost effectiveness of the BMD Fast Track program, the screening coordinators ordered a DXA test for patients rather than referring them to their primary care physicians. Refractures were limited to hip fractures and analyzed using the Markov model.

The FCS program prevented 3 hip fractures per 1,000 patients and the program improved QALYs by 4.3 years and led to increased costs of 83,000 Canadian dollar for every 1,000 patients screened, at a cost of $\$ 19,132$ per QALY gained. The Fast Track program could save an additional $\$ 5,720$ per QALY.

\section{Cost-effectiveness analysis of FLS $n$ US health-care system}

Post-fracture treatment rates in the US Medicare population are reported to be below $25 \%$.[8] This is due to the complex health care settings and fragmented nature of post-fracture care. Despite the development of the health care system, FLS has not been widely implemented in the US in 2014. Solomon et al. [8] developed a Markov statetransition computer simulation model to assess the costeffectiveness of an FLS in US health care system. They estimated the costs and benefits of an FLS, the probabilities of refracture while on osteoporosis treatment, as well as the utilities associated with various health states from published literature.

If 10,000 patients who had a hip fracture with an average life span of 8.6 years underwent usual care, the model projected 5,579 subsequent fractures: 1,958 hip fractures, 453 distal forearm fractures, 998 vertebral fractures, and 2,170 other fractures. However, if universal FLS applies to them, this model estimates that an FLS would result in 153 fractures (109 hip, 5 wrist, 21 spine, 17 other fractures), 37.43 more QALYs, and save $\$ 66,879$ compared with typical post-fracture care per every 10,000 post-fracture patients. 


\section{Cost-effectiveness of osteoporosis liaison service in Japan}

In Japan, the life expectancy at births in 2017 was 84.2 years, the highest in the world. And, the age-standardized all-cause mortality rates per 100,000 in 2017 were 567, the lowest in the OECD.[1] A nationwide survey of hip fractures in Japan reported that the total number of hip fractures in 2012 was 175,700, which is a significant increase compared to 116,800 in 2007.[18,19] The annual costs for osteoporotic fractures is estimated to be US $\$ 7,974$ to 9,895 billion, which is expected to increase in the future.[20] Moriwaki and Noto [21] conducted a patient-level state transition model-based cost-effectiveness analysis of 65-year-old women who experienced femoral neck fracture below BMD -2.5. In this study, secondary fracture prevention resulted in an additional lifetime cost of $\$ 3,396$ per person and conferred an additional 0.118 QALY, resulting in an incremental cost-effectiveness ratio of $\$ 28,880$ per QALY gained. According to the results of scenario analyses, Secondary fracture prevention by osteoporosis liaison service is cost-effective in Japanese women with osteoporotic hip fracture.

\section{CONCLUSIONS}

Osteoporosis and osteoporosis related fractures are major health concern not only in Korea but also in other developed countries. Mortality and comorbidity, as well as the medical cost of osteoporosis and osteoporosis related fractures, have a significant impact on the quality of life of patients and are socioeconomic burdens. Therefore, treating osteoporosis and preventing osteoporosis related fractures have become an essential element in Korean medical system. Despite the various differences in the health care system, hospitals in many other countries are operating FLS and they have confirmed its cost-effectiveness. In Korea's health care system, further research on cost-effectiveness as well as its clinical effects is needed.

\section{DECLARATIONS}

\section{Ethics approval and consent to participate Not applicable.}

\section{Conflict of interest}

No potential conflict of interest relevant to this article was reported.

\section{ORCID}

Yong Han Cha https://orcid.org/0000-0002-7616-6694

Yong-Chan Ha https://orcid.org/0000-0002-6249-0581

Jae-Young Lim https://orcid.org/0000-0002-9454-0344

Woo-Suk Kim https://orcid.org/0000-0001-6098-0117

\section{REFERENCES}

1. Organisation for Economic Cooperation and Development. Health at a glance 2019: OECD indicators. Paris, FR: OECD Publishing; 2019.

2. Kontis V, Bennett JE, Mathers CD, et al. Future life expectancy in 35 industrialised countries: projections with a Bayesian model ensemble. Lancet 2017;389:1323-35.

3. Ministry of Health and Welfare. Life expectancy and life expectancy excluding disease period. 2019 [cited by 2020 Jan 1]. Available from: http://www.index.go.kr/potal/main/ EachDtIPageDetail.do?idx_cd $=2758$

4. Cooper C, Campion G, Melton LJ, 3rd. Hip fractures in the elderly: a world-wide projection. Osteoporos Int 1992;2: 285-9.

5. Gullberg B, Johnell O, Kanis JA. World-wide projections for hip fracture. Osteoporos Int 1997;7:407-13.

6. Ha YC, Kim TY, Lee A, et al. Current trends and future projections of hip fracture in South Korea using nationwide claims data. Osteoporos Int 2016;27:2603-9.

7. Si L, Winzenberg TM, Palmer AJ. A systematic review of models used in cost-effectiveness analyses of preventing osteoporotic fractures. Osteoporos Int 2014;25:51-60.

8. Solomon DH, Patrick AR, Schousboe J, et al. The potential economic benefits of improved postfracture care: a costeffectiveness analysis of a fracture liaison service in the US health-care system. J Bone Miner Res 2014;29:1667-74.

9. Burge $\mathrm{R}$, Dawson-Hughes $B$, Solomon $\mathrm{DH}$, et al. Incidence and economic burden of osteoporosis-related fractures in the United States, 2005-2025. J Bone Miner Res 2007;22: 465-75.

10. Kim HY, Ha YC, Kim TY, et al. Healthcare costs of osteoporotic fracture in Korea: Information from the National Health Insurance Claims Database, 2008-2011. J Bone Metab 2017; 24:125-33. 
11. Watts JJ, Abimanyi-Ochom J, Sanders KM. Osteoporosis costing all Australians: a new burden of disease analysis 2012 to 2022. Glebe, AU: Osteoporosis Australia; 2013.

12. Parry JA, Langford JR, Koval KJ. Caregivers of hip fracture patients: The forgotten victims? Injury 2019;50:2259-62.

13. Ganda K, Puech M, Chen JS, et al. Models of care for the secondary prevention of osteoporotic fractures: a systematic review and meta-analysis. Osteoporos Int 2013;24: 393-406.

14. McLellan AR, Wolowacz SE, Zimovetz EA, et al. Fracture liaison services for the evaluation and management of patients with osteoporotic fracture: a cost-effectiveness evaluation based on data collected over 8 years of service provision. Osteoporos Int 2011;22:2083-98.

15. McLellan AR, Gallacher SJ, Fraser M, et al. The fracture liaison service: success of a program for the evaluation and management of patients with osteoporotic fracture. Osteoporos Int 2003;14:1028-34.

16. Major G, Ling R, Searles A, et al. The costs of confronting osteoporosis: cost study of an Australian fracture liaison service. JBMR Plus 2019;3:56-63.

17. Yong JH, Masucci L, Hoch JS, et al. Cost-effectiveness of a fracture liaison service-a real-world evaluation after 6 years of service provision. Osteoporos Int 2016;27:231-40.

18. Orimo $H$, Yaegashi $Y$, Hosoi $T$, et al. Hip fracture incidence in Japan: estimates of new patients in 2012 and 25-year trends. Osteoporos Int 2016;27:1777-84.

19. Orimo $H$, Yaegashi $Y$, Onoda $T$, et al. Hip fracture incidence in Japan: estimates of new patients in 2007 and 20-year trends. Arch Osteoporos 2009;4:71-7.

20. Harada A, Matsui Y, Takemura M, et al. Cost-utility analysis of osteoporosis. Nihon Ronen Igakkai Zasshi 2005;42:596608.

21. Moriwaki K, Noto S. Economic evaluation of osteoporosis liaison service for secondary fracture prevention in postmenopausal osteoporosis patients with previous hip fracture in Japan. Osteoporos Int 2017;28:621-32. 
